\title{
An Attempt to Restore the Ordinary Death to the Visual Realm-Artistic, Therapeutic, and Ethical Aspects of the Post-Mortem Photography of Children in the 21st Century. Short Introduction
}

\author{
Eucja Lange \\ University of Lodz, Poland \\ Polish Academy of Sciences, Poland
}

DOI: http://dx.doi.org/10.18778/1733-8077.16.3.07

\section{Keywords:}

Post-Mortem

Photography

of Children;

Bereavement Process;

Parent's Grief

\begin{abstract}
Post-mortem photography was a transcendental element in the $19^{\text {th }}$ century, which not only democratized portraiture, but also helped in the bereavement process. The comeback of post-mortem photography as a psychological tool helping parents of deceased children to cope with death was only a matter of time. The role and importance of memento-moris has to be taken into account in order to make significant changes in the grieving process, but all of the aspects of this kind of photography need to be considered. The artistic, therapeutic, and ethical dimensions of post-mortem photography in the $21^{\text {st }}$ century has its rules, and those rules need to be followed. The article constitutes only a part of the research devoted to the bereavement process from a sociological perspective.
\end{abstract}

Eucja Lange is a doctoral candidate in the Institute of Sociology at the University of Lodz and in the Institute of Literary Research at the Polish Academy of Sciences. She is an MA graduate in Theater Studies (2004), Ethnology and Culture Anthropology (2015), and the study of animal psychology (2018). In her recent research, she studies: the parents' experience of bereavement processes and the experience of cancer patients' suffering along with the phenomenon of cancertainment in its digital appearances. Her scientific interests focus on diversity issues, contemporary environmental social movements, gender studies, animal studies, and death studies.

email address: langel@o2.pl 


\section{The Tradition of Post-Mortem Photography}

I regard post-mortem photography (also called memento-mori here) as a valuable aid in the bereavement process; but to make it more understandable, there is a need to start with the $19^{\text {th }}$ century Victorian post-mortem photographs, or even go back to earlier cultural practices. Before the invention of photography individuals were celebrated and memorized through paintings and sculptures (see examples: Portrait of Hannibal Gustav Wrangel depicted as dead, 1643루 Portrait of a Deceased Girl, probably Catharina Margaretha van Valkenburg by Johannes Thopas, $\left.1682^{2}\right)$. It was a very limited method, affordable to the rich families only, or available to famous citizens. Most people kept artifacts, such as hair or personal belongings, to mourn the loved ones. Pelin Aytemiz (2011:1) mentions, referring to John Harvey, that to secure the memory of the recently deceased person, people kept charms, portraits, and "personal keepsakes" - as, for example, letters, jewelry, or clothing (see examples of mourning jewelry ${ }^{3}$ ). According to Elke Weesjes (2013), between 1839 and 1860, ambrotypes and tintypes took over the place of paintings and drawings or dead-masks, togeth-

\footnotetext{
1 Blog: Costume Cocktail. Posted on September 14, 2015. "Post mortem painting of Hannibal Gustav Wrangel, 1643." Retrieved November 27, 2019 (https://www.costumecocktail.com/2015/09/14/post-mortem-painting-of-hannibal-gustaf-wrangelsgatan-1643/).

${ }^{2}$ Blog: Costume Cocktail. Posted on September 14, 2015. “Portrait of a Deceased Girl, probably Catharina Margaretha van Valkenburg, 1682." Retrieved November 27, 2019 (https:// www.costumecocktail.com/2015/09/14/portrait-of-a-deceased-girl-probably-catharina-margaretha-van-valkenburg-1682/).

${ }^{3}$ Bond, Charlotte. 2018, December 05. “Somber 'Memento Mori' Jewelry Commissioned to Help People Mourn." The Vintage News. Retrieved November 27, 2019 (https://www.thevintagenews.com/2018/12/05/mourning-jewelry/).
}

er with the desire to immortalize the memory of a beloved family member. In the article about the tradition of the British post-mortem photography written by Audrey Linkman (2006:312), we may find the same information:

Post-mortem portraits were not limited to any specific class in British society. While relatively few people may have been able to afford a painting or drawing of a dead relative, photography brought portraiture within the financial reach of a wider section of society. Post-mortem photographs were commissioned both by the affluent and by people of more modest means.

Katherine Pettit (2006:35) refers to Jay Ruby focusing on the fact that it was also the time when death belonged to topics of polite conversations. The grieving process was considered normal (like wearing black in public, etc., sometimes months or even years after a death, which was implicated by the connection to the deceased) and the cemeteries were used as recreational sites where people were likely to take walks. Troy Cluff (2014:2) notes in his work that in Canada the post-mortem photography appeared at the same time as the cemetery reform movement inspired by Romanticism. The aesthetic aspect became important in the creation of more pleasing burial places. Death was something natural, something that awaited everyone, so there was no use in making it secret or shameful. The process of bereavement was a standardized social ritual, known to all, and that knowledge played an important role in the public reception of death.

The $19^{\text {th }}$ century, apart from being recognized as the age of progress, has also had a less friendly demographic effect. Especially in the first half of the 
Victorian era a high mortality rate prevailed. The unregulated migration resulted in overcrowding of the English cities, lack of housing, vagrancy, homelessness, unemployment, and epidemics of typhoid and cholera, which consequently led to more poverty and death. An important component in the high numbers of deaths was widespread infant mortality. It was natural and common to have numerous offspring, but surviving childhood required great internal resistance and favorable external circumstances. This was obviously due to the fact that children were least resistant to unsanitary living conditions and most vulnerable to diseases, as well as sensitive to malnutrition (Kamińska 2013:117-118). Therefore, we can find many photographs of deceased children as "the memory was central to the mourning process and photographs undoubtedly served to stimulate and perpetuate memory" (Linkman 2006:343). There was an expectation central to the Victorian practices of mourning and remembrance that the child's corpse would be depicted as exceedingly beautiful. It also appeared in consolatory literature where "the topos of the beautiful dead child is central...and is repeated over and over again in the letters of condolence, sermons, and poetry" (Brown 2009:14). This convention of a beautiful photo portrayal of dead children was called “sleeping angel" imagery (Iepson 2014:23).

In the American and European culture, post-mortem photography was a popular way of memorializing dead relatives. According to Ewelina Kamińska (2013:116), memento-mori photography was present in most of the countries of South America, North America, and Europe. In its original shape the way of depicting the dead remained unchanged. Various types of post-mortem photography are distinguished by different authors. One division can be done according to the historical periods and aesthetic changes through time. Another one focuses on the ways the deceased were depicted and here-according to Katherine Pettit (2006:36) - we can recognize three main styles of memento-moris. The first one would represent the dead in his or her last sleep (also in the already mentioned "sleeping angel" type; see an example: Deceased Child, Photographer unknown, photo circa $\left.1850^{4}\right)$. The second-alive, but dead-where the eyes were open or the pupils were painted on the eyelids, in an attempt to create an illusion that the subject was still alive. The grieving Victorians revealed a profound fascination and desire for immortality by creating fictional photographs that portray the deceased as alive. Additionally, the person could have a rosy tint on the cheeks (Munforte 2015); (see an example: Little Drummer Girl: Sarah A. Lawrence of 119 Hudson Avenue, photographer unidentified, Green Island, Albany County, New York, ca. 1847. ${ }^{5}$ Sixth-plate daguerreotype, hand colored. (C) Stanley B. Burns, MD \& The Burns Archive; www.burnsarchive.com). Thirdly, the deceased could be portrayed with mourners, which was also the idealization of the social institution of a middle-class family-parents depicted mourning their dead child. Sometimes only one parent (mostly the mother) appeared in the photos with the deceased child (see an example: An image of a mother posing with her dead child taken

\footnotetext{
${ }^{4}$ Website: Death \& Dying III. Post by Nicoleel on April 16, 2019. "Victorian Post-Mortem Photography." Photo of a Deceased Child, Photographer Unknown, circa 1850. Retrieved November 27, 2019 (http://idst190.web.unc.edu/author/nicoleel/).

5 Website: The Burns Archive. "The Death \& Memorial Collection." Little Drummer Girl: Sarah A. Lawrence, circa 1847. Retrieved November 27, 2019 (http://burnsarchive. com/EXPLORE/HISTORICAL/Memorial/index.html; https://www.incollect.com/sites/uploads/BurnsArchiveLittleDrummerGirl.jpg).
} 
in the USA, 1840s ${ }^{6}$ ). According to Dongjie Wang (2015:3), the fashion for the post-mortem photos was a bit deeper than a pure ritual:

The deceased were usually dressed in their best clothing and treated very respectfully in post-mortem photographs. The photographs of adults often showed mementos like rosaries and crosses in the folded arms. Many children were pictured alone, but a popular style was the family portrait with the deceased child in the center (Thanatos Archives). Part of the reason for this was to ease the grief of the living, but respect for the dead was another important factor. It was a common belief that the spirit of the dead did not leave until the funeral was over, so it was very important to include the deceased in ways that would make him or her feel as if they were still alive.

With time, the need to show the deceased as alive was less and less pressing. The new way of depicting dead people included showing the tragedy of death. The portraits were taken in coffins surrounded by candles and flowers, sometimes not at home but in funeral homes or churches (see an example: Girl in coffin. Herefordshire County Record Office ${ }^{7}$ ).

We need to know that not all people considered those pictures or death itself beautiful: seeing the dead as beautiful was something that had to

\footnotetext{
${ }^{6}$ Summers, Chris. 2016, December 15. "Stay Dead Still: The Gruesome 19th-Century Portraits of Children Who'd Passed Away which Helped Their Parents to Recover from Bereavement." Mail Online. Retrieved November 27, 2019 (https://www. dailymail.co.uk/news/article-4036412/Touching-morbid-gruesome-19th-century-portraits-dead-children-helped-parents-recover-bereavement.html).

${ }^{7}$ Clint, Edward. 2016, June 19. "Myths of Victorian Post-Mortem Photography." Incredulous. Retrieved November 27, 2019 (https:// www.skepticink.com/incredulous/2016/06/19/myth-victorian-post-mortem-photography/).
}

be learned. Additionally, not all photographers referred to this kind of photography in positive terms. The differences in attitudes towards the deceased and post-mortem photography in America and Britain can be illustrated by the article of Linkman (2006:312), who writes:

The Americans John Gihon and Albert Southworth managed to discuss the issue in print in a helpful, straightforward manner, which conveyed their pride in producing work of this nature to a high standard. By contrast, of the few British photographers prepared to put their names to articles about post-mortem portraiture, all saw lot to distance themselves to some degree from the work, describing it as unpleasant or distasteful. This suggests that British photographers were uncomfortable when discussing the topic in public. Most justified their involvement on the disinterested basis of the comfort the portrait would bring to the grieving relatives.

The British society was permeated by some other issues which photographers had to face: the fact that some remains of the dead could inflict a potential risk of infection or that more time had to be devoted to that kind of photography forced the photographers to set the prices that were higher and thus more profitable to undertake for them (Linkman 2006:315-316). Over the time, the practices and rituals changed and the need to go hand in hand with the dead child in a picture was no longer acceptable. Death lost its public nature, it was removed from the public sphere and relocated to the private sphere of life. According to Nicola Brown (2009:19), the meaning of the photos has changed-they were removed from view as something disgusting and not esthetic anymore. They also were "thrown away, or hidden, in family bibles, drawers, wallets, lockets or pockets. 
Some may have been transformed into relics by combining them with other mementos." They lost their devotional meaning with time and became ordinary objects.

This trajectory from intensely meaningful, treasured, touched objects to meaningless rubbish helps explain why so many of these photographs have disappeared from the complex of memories and feelings which made them so precious has grown distant and faded as time has passed. [Brown 2009:19]

The changes in mourning practices were brought about also by commercial photography, which became a tool for the documentation for the living. The invention of Kodak cameras turned everybody into photographers, who could take photos, so the photographs became more and more private and rather hidden from view (Wang 2015:5). In the $20^{\text {th }}$ century the infant mortality dropped and the death was connected mostly with elderly people (Weesjes 2013). The post-mortems seemed to be lost for good, while contact with the deceased and with their corpse relatives only experienced during funerals, when the body was not always visible (as the coffin may be closed). But, still, there were some individuals and groups that practiced amateur post-mortem photography, whose examples can be found in the circles of African Americans, Asian Americans, and Polish Americans (the photographs in the coffin or ordered from the funeral home). In Poland, this kind of tradition was and continues to be most vivid in the country and it has not changed much.

\section{Contemporary Memento-Mori Photography}

A contemporary example of memento-mori photography appeared in America a few years ago. Now
I Lay Me Down To Sleep, ${ }^{8}$ which is a Colorado-based non-profit volunteer organization, was founded in April 2005 by Cheryl Haggard and Sandra Puc. On the $4^{\text {th }}$ of February 2005, Maddaux, Cheryl's son, died. A photographer and a friend of Cheryl, Sandra Puc, took some photos of Maddaux and his parents-all in a tasteful black-and-white convention. As for now (2017) the website of this project announces that there are 1700 active photographers around the world who are volunteers that can be asked to provide grieving families with memento-moris. I shall add that this is not the only professional service in the United States of America offered to parents who lost their children and there are some freelance photographers around the world also providing such services to parents who experience an early infant loss.

It is said that this kind of organization has changed the attitude towards child death. Before the 1970s medical staff often prevented parents from seeing and holding their stillborn babies and also encouraged families to quickly forget their loss (Blood and Cacciatore 2014a:2). The conducted research showed, however, that there was a need for a continuing bond which had to be reorganized (Bowlby 2016). The custom of memorial images is now offered in almost all hospitals in the United States, which can be highlighted as a good practice. Of course, there are a lot of questions about the efficiency of this kind of help. Some studies stress the fact that to be sure if the post-mortem photography is crucial in the parents' bereavement process, there should be appropriate research in place to assess all the aspects and potential effects (Harvey, Snowdon, and Elbourne 2008:352-353). Some

\footnotetext{
${ }^{8}$ Now I Lay Me Down to Sleep. Official website of the organization. Retrieved November 27, 2019 (https://www.nowilaymedowntosleep.org/).
} 
researchers have investigated the effectiveness of bereavement interventions in neonatal intensive care (Harvey, Snowdon, and Elbourne 2008:353) and suggest that:

Experimental research may well be difficult, but not beyond the realms of possibility...A mixed-methods approach such as this would provide data on effectiveness, as well as preferences, and could be used to explore wider practical and ethical questions, such as who should take the photographs, how, when, and where? When should they be given to parents: at an early stage, on leaving the hospital, or at a follow-up visit? Who should have responsibility for this: photographers, nurses, bereavement counselors, or consultants? Style and content of photographs can differ, and reactions to those should be explored. It would be appropriate to consider not only whether parents want to have these images, but also whether parents, siblings, or wider family members need and respond to them in the same way.

The pictures are regarded by parents who took part in this project as "wonderful artifacts that document an unspoken part of our social history and can be seen as icons or reminders of love and loss" (Weesjes 2013). The grief counseling and death education in public schools in the United States of America slightly changed the pathological indication of public display of mourning over the death of a family member. Also, modern digital photography made memento-mori photography more available to all those who need it. But, as Angela Riechers (2008:3) points out, the amateur "often blurry, poorly lit" images were for many parents the only evidence of stillborn baby existence.

Katherine Pettit (2006), referring to Sigmund Freud and Thierry de Duve, states that in order to survive and heal, a mourning person has to direct his or her attention towards someone or something else. In Poland, still it is mostly understood as: "have another baby," but some psychiatrists see the chance of building a new bond with the deceased, through the substitutive objects, such as belongings or images, that can help ease the grieving process. This idea of remodeling the bond between the parents and their deceased child is based on the theory of attachment and loss by John Bowlby (2016). In addition, the sociological approach focuses on holding on to memories in an attempt to redefine the identity after loss (Komaromy et al. 2009:7).

The visual culture manifests itself in five ways that give the society of late modernity five specific features. Piotr Sztompka (2012:15-20) points to the icon, spectacle, self-presentation, design, and voyeurism as the main visual dimensions of the society we are living in. Its natural consequence is the usage of images for different purposes, for instance, therapeutic ones. Due to its indexical nature, the photography makes a mourning process occur with almost every photograph. And, all photos are memento-morias stated by Susan Sontag (2009:23). It is due to the fact that all photos represent past in the Barthesian meaning-the viewer is always aware that the subject or the object of the image once existed in a certain time and place, but it does not exist in the same way at the time of viewing the photography (Barthes 1996:157-162). The photography is a copy of the real object and an emanation of the past-something connected with magic, art, and a metaphor of resurrection. Thus, we can think about all photographs in the category of memento-mori as they continually remind us of death (Ferenc 2011).

Cybele Blood and Joanne Cacciatore (2014b:224) refer to the studies that show "bereaved parents 
endure profoundly painful emotions, significant challenges of their worldview, and a compromised sense of identity, with risk of negative psychiatric outcomes." In the subject of perinatal death, "they face the additional burden, as their baby is not socially recognized as significant." Therefore, the reappearance of memento-mori photography in perinatal death protocol was and continues to be a change that was needed and expected by parents. But, we need to bear in mind the fact that "parents are affected differently and grieve in different ways" (Kohner 2000:358). It means that we can find parents who do not want help and photos, they just want to forget and move on. There can be many reasons behind the decision to refrain from taking part in that kind of service, such as disfigurations of the body, violent cause or circumstances of death, preferences to have only photos of alive children, religious, or cultural ideas. Sometimes the situation makes parents feel confused and the state of shock does not promote the recognition that a photograph of a child may actually help to ease the pain in the future (Blood and Cacciatore 2014a:4-5).

\section{The Importance of Aesthetic, Therapeutic, and Ethical Aspects}

I have already mentioned that the post-mortem photography has had a great value to the mourners. Some researchers highlight the fact that it was not entirely clear what motives were behind the fashion of memento-mori photography in the $19^{\text {th }}$ century. In particular, the photographs' reception by family members is for us unknown as they were never the object of study (Iepson 2014:16). However, there are studies devoted to the reception of post-mortem photos by parents of deceased children-they may not be the most relevant as the subject is still under research, but they already tell us much. We are not only aware of such photographs' effects on people and their preferred outlook and style, but we know what should not be shown in order to respect the rules of therapeutic values.

The aesthetics is very important in this delicate subject. The photographs should be prepared in a black-and-white artistic manner. It is a reference to the traditional post-mortem photography, on the one hand, and a therapeutic tool, on the other. They cannot show any indications of pain. Parents ask for photographs without any kind of medical equipment on the face (Harvey, Snowdon, and Elbourne 2008:353). If the baby's body is somehow deformed, the photography should disguise that fact and leave parents with more positive memories of their deceased baby. Sometimes parents want to be with the child in the picture, so the photography should express also the love and grief of the family members in the photo-the research shows that the parents feel the need to have an image with the baby, "even if it was taken shortly after one baby had died" (Harvey, Snowdon, and Elbourne 2008:353). The motive behind the commissioning of post-mortem photographs in most cases is the desire to recall the face of the deceased child, because the only present feelings are pain and loss. Therefore, it should be considered to help create the bond and a healthy relation with the mourned child. Thus, sometimes the retouch service is provided in order to create a picture that will help to fade away all the bad memories.

Sometimes artists are approached to create memento-mori photographs in colors, but these tend to show not only the skin tones, but also resemble some common photographs of healthy babies in decorations and have a connotation of fluffy, fun- 
ny stuff. These kinds of pictures can trigger bad experiences connected with still-birth or other unpleasant things and greater feelings of loss, as the baby is no longer present and the images may also inadvertently reveal the pain of the child, which is overwhelming for parents dealing with their feelings.

Blood and Cacciatore (2014b:225) in their research assume that:

- visual imagery helps in the creation of parental identity when a baby has died (especially important for fathers, as the bond with the mother is natural and obvious);

- photographs help to establish a social identity for the deceased child;

- photographs help parents to create narratives to share with others (and narratives are crucial in coping with grief, helping to reconstruct meaning and repair existential crises);

- symbolic activities help embed painful memories, thoughts, and feelings into narrative structure (rituals offer meaning, validate loss, and mediate transition in identity during the grief process);

- photographs may allow more immediate access to memories and feelings;

- photographs help integrate emotional and cognitive processes (they work as transitional objects, simultaneously filling a void).

The value of the post-mortem photography is also a symbolic closure and a part of the rite of pas- sage documentation. Anna Pietrzyk (2015:547) concludes in her anthropological study of the Polish funeral photography tradition that the currently present ambivalent attitude towards digital or analogue post-mortem photographs indicates that the photography still affects modern people, forcing them to react, which, though different and dependent on the individual character and sensitivity of a person (aversion, fear, disgust, crying, remembering the deceased family members, nostalgic return to a time in life when the death took place, and telling family stories), certainly confirms the persistence mechanism of the image-instigated interaction.

Why is it so important to adhere to the therapeutic aspect of the photography in its aesthetic blackand-white version? For most of the parents who lost their child, there is nothing more terrible in life that could ever happen. They feel as if they could never be alive again and that there is nothing left for them (even if they have other children), only the grief which replaces the lost child. Louise J. Kaplan (1995:118) observes that:

When a child dies, the parent loses a vital aspect of her own self. The flesh-and-blood child, his tangible presence in the world, is evidence of the parent's meaning in life. When a child dies, the parent longs for actual conversations with the actual child. Unlike the child who, when a parent dies, finds some way to reproduce the parent within her own self, when a child dies, the palpable presence of grief is all that is left for the parent...A dead child can only be memorialized in the parent's grief.

The photographs help to preserve memories, prevent inaccurate memories, honor the child, and 
create a way to be with the child. It is crucial to the mourning process to create most appropriate conditions that will help to transform the bond and ease the grief. Sometimes it means also improving the reality and retouching photos or even creating a vision of the realm that will be more comforting-to avoid parents' reactions that can be summarized as "painful" or "hard to look at" (Blood and Cacciatore 2014b:228). Post-mortem photography is transforming pain into symbolic representation, which allows experiencing and taming it at once.

\section{Conclusions}

In conclusion, there are three aspects of post-mortem photography in the $21^{\text {st }}$ century: 1 ) the ethical aspect, according to which we need to consider the cultural and religious beliefs of the parents concerned, as not all of them want to participate in that kind of practice and not all of them need that kind of practice (Blood and Cacciatore 2014b:226; $229) ; 2)$ the therapeutic aspect, which was highlighted by most of the parents from the survey taken by Blood and Cacciatore (2014a; 2014b) and can be specified as "not only contemplation of the image that produces the emotions...but the tactility of the photographs as object" (Brown 2009:21); and 3) the artistic aspect, which postulates that pictures should be taken in black-and-white, not to recall the actual colors, which may instigate bad memories. If needed, they should be retouched, cropped, and lit in an appropriate way.

I agree with Sheila Harvey, Claire Snowdon, and Diana Elbourne (2008:353) that the only way to research contemporary post-mortem photography is through a "mixed-methods approach." We may focus on the practical use of the memen- to-mori pictures and their social values in restoring "the ordinary death." We may also try to explore the ethical aspects together with aesthetical preferences of parents and their reactions. There is also the interesting part of symbolic interaction between all the actors involved (parents, the deceased child, photographers, nurses, counselors), the space (hospital), and the things (photos). The sociological lenses give us a great area to explore the rituals that have arisen around this "new" practice and answer the questions-how the pictures help, how parents use them, what is their place in the lives of people mourning?

According to Aténé Mendelyté (2012:84), "these pictures have the ability to affect us deeply despite their remote historical and cultural context, and...behind the perceptual inconclusiveness of these images lurks the fear of facing our own finitude." And, as the last thought, I would like to quote John Berger, ${ }^{9}$ who once said:

All photographs are there to remind us of what we forget. In this-as in other ways-they are the opposite of paintings. Paintings record what the painter remembers. Because each one of us forgets different things, a photo more than a painting may change its meaning according to who is looking at it.

We should not forget about death, we shall embrace the idea of dying. This can help to deal with the pain and loss, this can also help to understand how the pain can be overcome by stimulation of the appropriate senses.

\footnotetext{
9 “Quote by John Berger." Quotery. Retrieved November 27, 2019 (http://www.quotery.com/quotes/all-photographs-are-there-toremind-us-of-what-we/).
} 


\section{References}

Aytemiz, Pelin. 2011. “Death as Absence: Death Related Photographic Representations." Draft paper. Retrieved November 27, 2019 (http://www.inter-disciplinary.net/wp-content/uploads/2011/10/aytemizdpaper.pdf).

Barthes, Roland. 1996. Światto obrazu. Uwagi o fotografii [Camera Lucida: Reflections on Photography]. Warsaw: Wydawnictwo KR.

Blood, Cybele and Joanne Cacciatore. 2014a. "Best Practice in Bereavement Photography after Perinatal Death: Qualitative Analysis with 104 Parents." BMC Psychology 2:15. Retrieved November 27, 2019 (http://bmcpsychology.biomedcentral.com/articles/10.1186/2050-7283-2-15).

Blood, Cybele and Joanne Cacciatore. 2014b. "Parental Grief and Memento Mori Photography: Narrative, Meaning, Culture, and Context." Death Studies 38:224-233.

Bowlby, John. 2016. Przywiazanie [Attachment]. Warsaw: Państwowe Wydawnictwo Naukowe.

Brown, Nicola. 2009. "Empty Hands and Precious Picture: Post-Mortem Portrait Photographs of Children." Australasian Journal of Victorian Studies 14(2):8-24.

Cluff, Troy. 2014. Peaceful Ironies: The History and Aesthetics of Postmortem Photography in Quebec and Ontario (19th and 20th Centuries). MA Dissertation, Concordia University in Montreal, Quebec. Retrieved November 27, 2019 (http://spectrum.library. concordia.ca/978903/1/Cluff_MA_F2014.pdf).

Ferenc, Tomasz. 2011. “Fotografia i śmierć - historia pewnego uwikłania i realna styczność [Photography and Death-The Story of a Certain Entanglement and Real Contact]." Kwartalnik Fotografia 35. Retrieved November 27, 2019 (https://www.academia.edu/4742794/Fotografia_i_\%C5\%9Bmier\%C4\%87).

Harvey, Sheila, Snowdon Claire, and Diana Elbourne. 2008. "Effectiveness of Bereavement Interventions in Neonatal Intensive Care: A Review of the Evidence." Seminars in Fetal $\mathcal{E}$ Neonatal Medicine 13:341-356.

Iepson, Sarah M. 2014. "Perpetual Corporeality. Affect Theory and Posthumous Photographs of Children in Nineteenth-Century America." Journal of the Lucas Graduate Conference 2:12-28.
Kamińska, Ewelina. 2013. “Między śmiercią, fotografią i antropologią. Kilka uwag o XIX-wiecznej i współczesnej fotografii post mortem [Between Death, Photography and Anthropology. A Few Remarks on $19^{\text {th }}$ Century and Contemporary Post Mortem Photography]." Okolice. Rocznik Etnograficzny 11:115-129.

Kaplan, Louise J. 1995. Lost Children. Separation and Loss between Children and Parents. Glasgow: Harper Collins Manufacturing.

Kohner, Nancy. 2000. "Pregnancy Loss and the Death of a Baby. Parents' Choices." Pp. 355-359 in Death, Dying and Bereavement, edited by D. Dickson, M. Johnson, and J. Samson Katz. London: SAGE Publications.

Komaromy, Carol et al. 2007. "A Social Insight into Bereavement and Reproductive Loss." Retrieved November 27, 2019 (http://oro.open.ac.uk/12653/1/A_social_insight_into_bereavement_and_reproductive_loss.pdf).

Linkman, Audrey. 2006. "Taken from Life: Post-Mortem Portraiture in Britain, 1860-1919." History of Photography 30(4):309-347.

Mendelyté, Aténé. 2012. "Death (in the Eye) of the Beholder: An Encounter with Victorian Post-Mortem Photography." Synaesthesia: Communication Across Cultures 1(3):84-90.

Munforte, Patrizia. 2015. "The Body of Ambivalence: The 'Alive, Yet Dead' Portrait in the Nineteenth Century." Re $e^{*}$ bus 7:75-104.

Pettit, Katherine. 2006. "Metamorphic Death: Post-Mortem \& Spirit Photography in Narrative Cinema." Cinephile 2:3539.

Pietrzyk, Anna. 2015. “Fotografia pogrzebowa w polskiej obyczajowości wczoraj i dziś [Funeral Photography in Polish Customs Yesterday and Today]." Ogrody Nauki i Sztuki 5:541-551.

Riechers, Angela. 2012. “Eternal Recall: Memorial Photos in the Digital Environment." Retrieved November 27, 2019 (https://core.ac.uk/display/21728921). 
Sontag, Susan. 2009. O fotografii [On Photography]. Cracow: Wydawnictwo Karakter.

Sztompka, Piotr. 2012. "Wyobraźnia wizualna i socjologia [Visual Imagination and Sociology]." Pp. 11-42 in Fotospołeczeństwo. Antologia tekstów z socjologii wizualnej [Photo-Society. Anthology of Texts from Visual Sociology], edited by M. Bogunia-Borowska and P. Sztompka. Cracow: Wydawnictwo Znak.
Wang, Dongjie. 2015. "A History of Post-Mortem Photography." Retrieved November 27, 2019 (http://www2.ohlone.edu/org/library/ wang.pdf).

Weesjes, Elke. 2013, April 3. “'Don't Move'-A Short History of Post-Mortem Photography." United Academics Blog. Retrieved November 27, 2019 (https://www.academia.edu/8837116/Dont_ Move_-_A_Short_History_of_Post-Mortem_Photography).

\section{Citation}

Lange, Łucja. 2020. "An Attempt to Restore the Ordinary Death to the Visual Realm-Artistic, Therapeutic, and Ethical Aspects of the Post-Mortem Photography of Children in the 21st Century. Short Introduction." Qualitative Sociology Review 16(3):106-116. Retrieved Month, Year (http://www.qualitativesociologyreview.org/ENG/archive_eng.php). DOI: http://dx.doi. org/10.18778/1733-8077.16.3.07 